\title{
EFEITO DO INÓCULO NA OBTENÇÃO DE PECTINASES POR Aspergillus fumigatus
}

\author{
C. REGINATTO, F. P. NORONHA, C. ROSSI, S. CARRA, L. MENEGHEL, \\ M. MOURA da SILVEIRA, E. MALVESSI \\ Universidade de Caxias do Sul, Instituto de Biotecnologia \\ E-mail para contato: c.b.reginatto@gmail.com
}

\begin{abstract}
RESUMO - O inóculo exerce influência direta sobre o crescimento celular e o tempo de processo de obtenção de pectinases por fungos filamentosos. Neste trabalho foram avaliados o crescimento e a produção de pectinases por Aspergillus fumigatus LB-01-AP com o uso de inóculo vegetativo, em proporções de 5 e $10 \%(\mathrm{v} / \mathrm{v})$, em comparação com a inoculação por suspensão de esporos. A suspensão foi obtida da cultura incubada em meio sólido, por 96h. Para a obtenção de inóculo vegetativo, A. fumigatus foi cultivado em frascos Erlenmeyer com $100 \mathrm{~mL}$ de meio, mantidos a $300 \mathrm{rpm}$ e $28^{\circ} \mathrm{C}$, por $30 \mathrm{~h}$. Estas condições operacionais foram usadas nos cultivos de produção de pectinases, porém, por 120h. Com a utilização de esporos, observou-se fase lag de crescimento de cerca de $18 \mathrm{~h}$. Este período foi cerca de $50 \%$ inferior com o uso de inóculo vegetativo, com a obtenção de maiores títulos de biomassa e sem influência sobre a máxima velocidade específica de crescimento celular. A utilização de inóculo vegetativo proporcionou a obtenção de atividade de pectinases totais superior, alcançando valores máximos de11 e $13 \mathrm{U} / \mathrm{mL}$, com 5 e $10 \%(\mathrm{v} / \mathrm{v})$, respectivamente, em $75 \mathrm{~h}$. No ensaio controle, o pico de atividade $(9,2 \mathrm{U} / \mathrm{mL})$ foi observado em $120 \mathrm{~h}, 45 \mathrm{~h}$ após os picos obtidos com a utilização de inóculo vegetativo. Os resultados sugerem a possibilidade de uso de inóculo vegetativo em estudos posteriores em biorreator como forma de reduzir o tempo e o custo operacional do processo.
\end{abstract}

\section{INTRODUÇÃO}

A utilização de enzimas vem ganhando espaço em processos industriais devido à necessidade do desenvolvimento de novas tecnologias, atendendo as tendências do mercado por produtos de menor impacto ambiental. Dentre as enzimas produzidas comercialmente, destacam-se as enzimas pécticas, amplamente utilizadas em processos industriais, cujos primeiros registros de utilização comercial são da década de 1930 (Jayani et al., 2005). Desde então, as pectinases vem sendo cada vez mais utilizadas, principalmente na indústria de alimentos, sendo extensivamente empregadas na produção de sucos de frutas e vinhos. Estas enzimas atuam na degradação de substâncias pécticas presentes na parede celular de vegetais e frutos, facilitando os processos de extração e de clarificação (Kashyap et al., 2001; Gummadi e Panda, 2003; Uenojo e Pastore, 2007).

Entre os microrganismos capazes de sintetizar enzimas pectinolíticas, os fungos filamentosos são amplamente utilizados pelo fato de as pectinases por eles produzidas 
atuarem numa faixa de $\mathrm{pH}(3,0$ a 5,5) compatível com a utilizada na produção de sucos de frutas. Além disso, cerca de $90 \%$ destas enzimas são secretadas no meio de cultivo, facilitando a recuperação e a purificação (Ueda et al., 1982; Uenojo e Pastore, 2007). Vários fungos do gênero Aspergillus são listados na Resolução RDC 26/2009 da ANVISA (Agência Nacional de Vigilância Sanitária) como seguros para a utilização na produção de pectinases.

Em cultivos submersos de fungos filamentosos, entre os processos prévios à fermentação, a forma de inoculação pode influenciar o perfil de crescimento e a morfologia celular (Moraes, 2001; Papagianni e Moo-Young, 2002). A inoculação pode ser realizada a partir de uma suspensão de esporos, a partir de uma cultura estoque, ou com adição de uma proporção definida de biomassa (Moraes, 2001). Em estudos relacionados à forma de inoculação, Papagianni e Moo-Young (2002) verificaram que, ao utilizar inóculo vegetativo de $A$. niger, maiores títulos de biomassa e de atividade de glicoamilases foram atingidos. No entanto, os autores salientam que a velocidade específica de crescimento foi inferior à obtida em cultivo inoculado com esporos, relacionando esse comportamento à morfologia do microrganismo.

Neste contexto, este trabalho teve por objetivo avaliar o crescimento celular e a produção de pectinases por A. fumigatus, comparando-se a inoculação com suspensão de esporos com a utilização de diferentes proporções de inóculo vegetativo.

\section{MATERIAIS E MÉTODOS}

O microrganismo utilizado foi A. fumigatus LB-01-AP, pertencente à coleção de culturas do Laboratório de Bioprocessos (UCS). Para a produção de pectinases foi utilizado o meio de cultivo adaptado de Fontana et al. (2009), composto de extrato de farelo de trigo $(80 \mathrm{~g} / \mathrm{L})$, glicose $(22 \mathrm{~g} / \mathrm{L})$, pectina $(20 \mathrm{~g} / \mathrm{L})$, extrato de levedura $(0,05 \mathrm{~g} / \mathrm{L})$ e sais.

Os meios foram preparados em frascos Erlenmeyer de $500 \mathrm{~mL}$, com gargalo alongado, com $100 \mathrm{~mL}$ de volume útil, cobertos com gaze e algodão hidrófobo, autoclavados a 1atm, por 15 minutos, após correção do $\mathrm{pH}$ inicial para 4,0 com $\mathrm{NaOH} 2,5 \mathrm{M}$ ou $\mathrm{HCl}$ 2,0M. Os cultivos foram conduzidos sob agitação recíproca (equipamento construído na UCS), a $300 \mathrm{rpm}$ e $28^{\circ} \mathrm{C}$, por $120 \mathrm{~h}$. Amostras periódicas foram coletadas para a avaliação do $\mathrm{pH}$, do crescimento celular, do consumo de substrato e para a determinação da atividade pectinolítica.

Para os meios inoculados com suspensão de esporos (ensaio controle), utilizou-se a concentração de $10^{8}$ conídios $/ \mathrm{mL}$. Para os meios em que foi empregado inóculo vegetativo, testaram-se as proporções de 5\% e 10\% (v/v) (ensaios F5 e F10, respectivamente). O inóculo vegetativo foi previamente preparado em frascos contendo $100 \mathrm{~mL}$ de meio isento de pectina, inoculados com suspensão de esporos, incubados e mantidos sob agitação, por $30 \mathrm{~h}$.

O crescimento celular foi avaliado por gravimetria. A concentração de açúcares redutores totais (ART) foi determinada de acordo com o método descrito por Bitmann (1974) e modificado por Meneghel (2013) para amostras isentas de sólidos em suspensão. Salienta-se que a pectina presente no meio não é hidrolisada e, deste modo, não exerce influência sobre a avaliação dos resultados relativos ao consumo de substrato. A atividade de pectinases totais 
foi avaliada pelo método descrito por Maiorano (1990) e modificado por Malvessi (2000) para a determinação de endo-poligalacturonases. $\mathrm{O}$ método é baseado na medida da redução da viscosidade de uma solução padrão de pectina $0,63 \%(\mathrm{~m} / \mathrm{v})$, submetida à ação de enzimas pectinolíticas que rompem as ligações glicosídicas internas da cadeia de ácido poligalacturônico. No entanto, considerando-se que, para redução da viscosidade, todo o complexo pectinolítico deve atuar, os resultados, neste trabalho, serão expressos como pectinases totais.

A máxima velocidade específica de crescimento celular $\left(\mu_{\mathrm{X}, \max }\right)$ foi estimada a partir do coeficiente angular da reta resultante do ajuste linear dos pontos experimentais, em representação semilogarítmica da concentração celular com o tempo de cultivo, durante a fase exponencial de crescimento. Nesta fase, a velocidade específica do crescimento é constante e máxima (Hiss, 2001). Os fatores de conversão de substrato em produto ( $\left.\mathrm{Y}_{\mathrm{P} / \mathrm{S}}\right)$ e em células $\left(\mathrm{Y}_{\mathrm{X} / \mathrm{S}}\right)$ foram calculados a partir dos máximos valores de atividade enzimática $\left(\mathrm{P}_{\max }\right)$ e de concentração de biomassa $\left(\mathrm{X}_{\max }\right)$, levando-se em consideração a concentração de substrato consumido até período em que estes parâmetros foram determinados.

\section{RESULTADOS E DISCUSSÃO}

No cultivo de A. fumigatus, utilizando-se suspensão de esporos como inóculo (ensaio controle), foi observada uma fase lag de, aproximadamente, $18 \mathrm{~h}$ (Figura 1). Valores de $\mathrm{pH}$ em torno de 4,0 e baixo consumo de substrato foram observados neste período, indicando o reduzido metabolismo microbiano, uma vez que a queda do $\mathrm{pH}$ estaria relacionada à formação de ácidos provenientes da atividade celular.

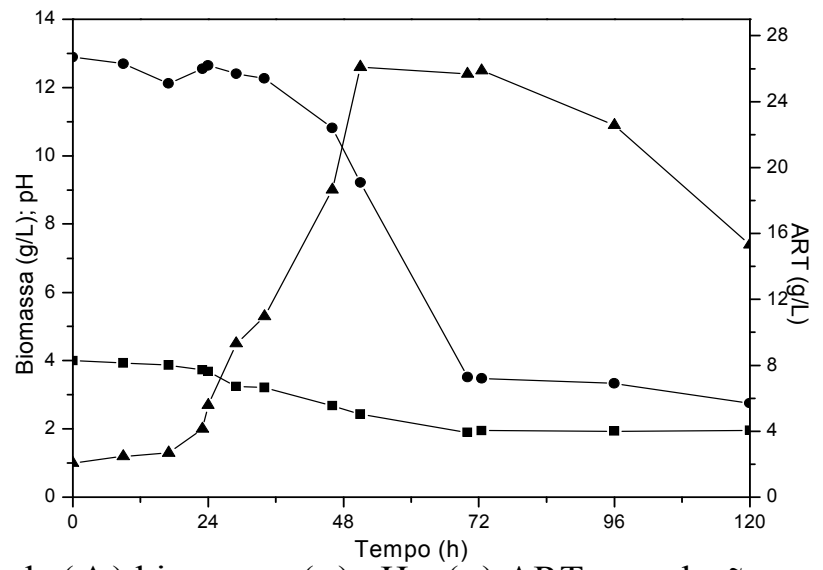

Figura 1 - Variação de $(\boldsymbol{\Delta})$ biomassa, $(\boldsymbol{\bullet}) \mathrm{pH}$ e (•) ART em relação ao tempo de cultivo de Aspergillus fumigatus em frascos sob agitação, no ensaio controle (inóculo com suspensão de esporos).

A análise do perfil de crescimento, mostrado na Figura 1, sugere que o início da fase exponencial de crescimento celular ocorreu em torno de $18 \mathrm{~h}$ de cultivo, sendo atingida concentração máxima de biomassa $(12,5 \mathrm{~g} / \mathrm{L})$ em $51 \mathrm{~h}$. Queda do $\mathrm{pH}$ para valor próximo a 3,0 foi observada na fase de intenso crescimento, mantendo-se em torno de 2,0, a partir de $72 \mathrm{~h}$ até o final do cultivo. Redução gradual na concentração de ART foi observada até $72 \mathrm{~h}$, sendo 
determinado $6 \mathrm{~g} / \mathrm{L}$ de substrato quando o cultivo foi encerrado, em $120 \mathrm{~h}$. Esta concentração de substrato residual possivelmente está relacionada à presença de espécies redutoras não metabolizáveis por este microrganismo ou, ainda, pela escassez de algum nutriente essencial ao metabolismo celular.

A utilização de inóculo vegetativo foi avaliada a fim de levar à redução do tempo de cultivo relacionado à fase lag ou de adaptação de A. fumigatus. A diminuição do tempo de processo acarretaria em menor gasto energético e em aumento da produtividade, fatores importantes em se tratando de aumento de escala, visando à produção industrial. Para a avaliação do emprego de inóculo vegetativo conduziu-se um cultivo em meio isento de pectina, por $39 \mathrm{~h}$, para determinar o tempo necessário para que a população microbiana atingisse a fase exponencial de crescimento. Optou-se por conduzir este ensaio em ausência de pectina a fim de facilitar a transferência de oxigênio para o microrganismo, uma vez que este composto confere alta viscosidade ao meio de cultivo. Os resultados estão mostrados na Figura 2.

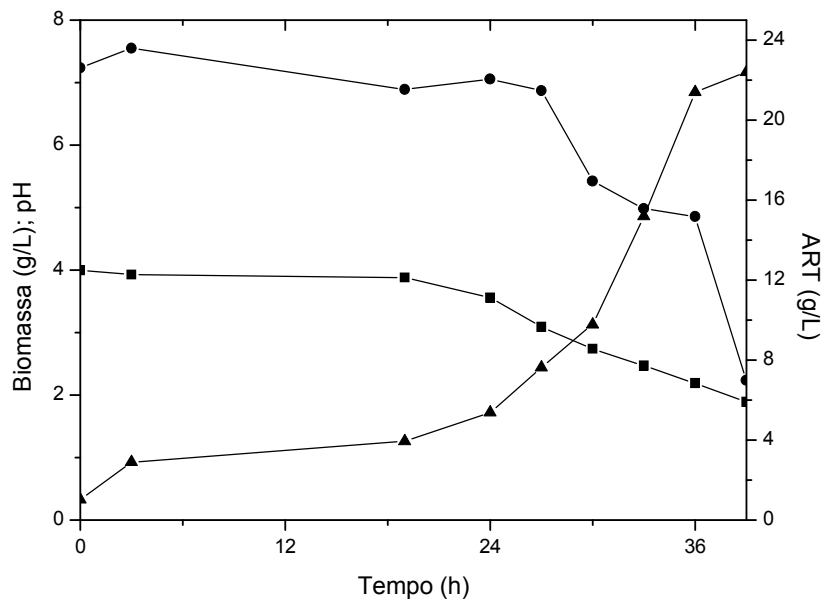

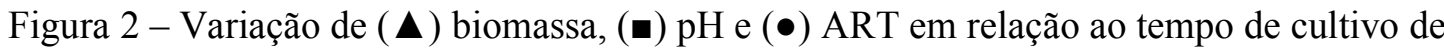
Aspergillus fumigatus em frascos sob agitação, no ensaio para a determinação do inóculo vegetativo.

A partir dos valores obtidos de concentração de biomassa (Figura 2), a fase exponencial de crescimento microbiano foi identificada entre 18 e $30 \mathrm{~h}$ de processo, aproximadamente. Nesse período, valores de pH próximos a 3,0 e consumo de substrato (ART) em torno de $30 \%$ do valor inicial foram observados. Assim, optou-se por utilizar o inóculo de $30 \mathrm{~h}$ de cultivo, garantindo que neste tempo o microrganismo ainda encontra-se em fase de intenso crescimento celular e não na fase estacionária.

Posteriormente, foram realizados os cultivos F5 e F10, empregando-se 5 e $10 \%$ (v/v) de inóculo vegetativo, respectivamente. Os resultados experimentais destes cultivos são apresentados na Figura 3. Observou-se aumento da concentração celular a partir de $9 \mathrm{~h}$ de cultivo, acompanhado de queda do $\mathrm{pH}$ e da concentração de substrato, indicando atividade metabólica microbiana. Comportamento similar foi observado no ensaio controle (Figura 1), porém apenas após $18 \mathrm{~h}$ de cultivo. Máximas concentrações celulares foram estimadas por volta de 40h para os cultivos F5 (14g/L) e F10 (15g/L), observando-se redução para 8 e $10 \mathrm{~g} / \mathrm{L}$ 
após 96h, mesmo em presença de substrato residual no meio. Este fato, conforme já discutido para o ensaio controle, pode ter sido decorrente da presença de substâncias redutoras não metabolizáveis por esse microrganismo ou pela escassez de algum nutriente essencial ao metabolismo do fungo.

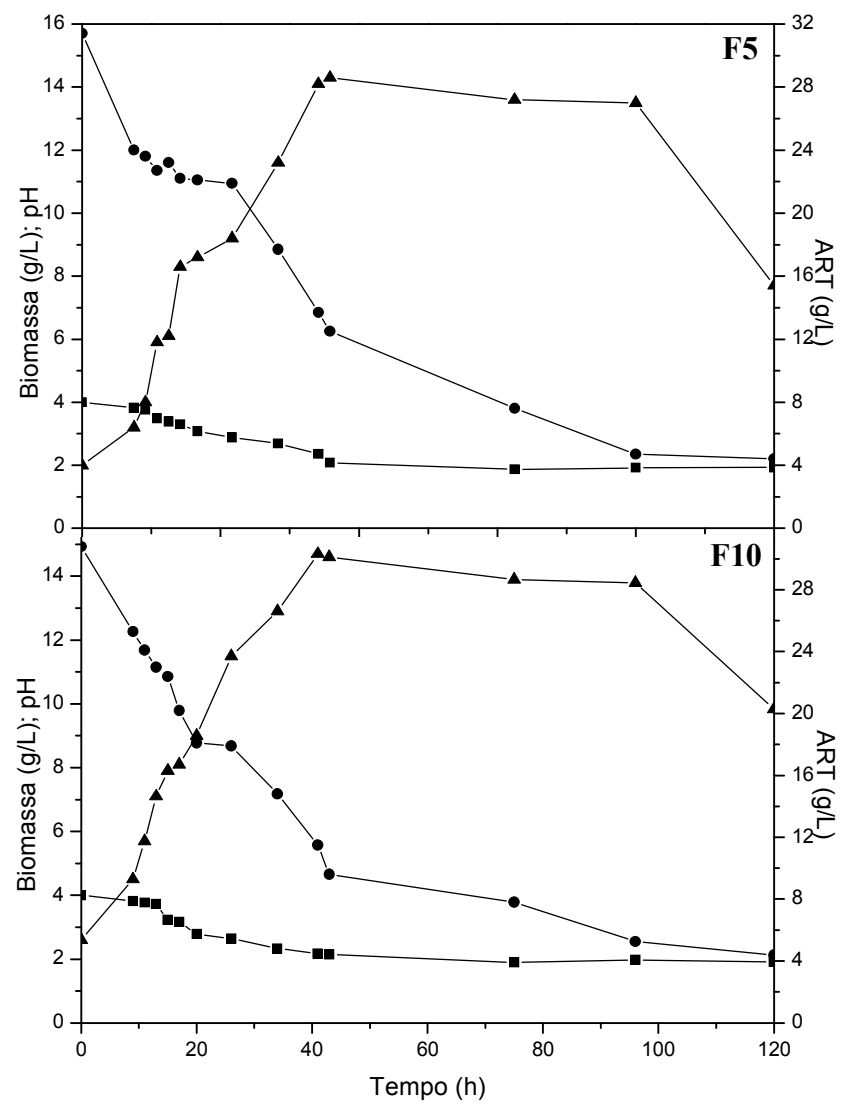

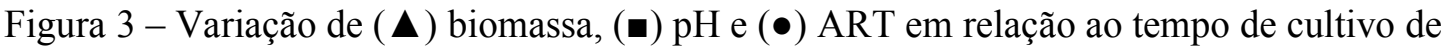
Aspergillus fumigatus em frascos sob agitação, com a utilização de inóculo vegetativo em diferentes proporções: F5 (5\% v/v); F10 (10\% v/v).

As máximas velocidades específicas de crescimento celular $\left(\mu_{\mathrm{X}, \max }\right)$ foram definidas a partir do coeficiente angular da reta obtida através da representação logarítmica da concentração celular em função do tempo. Os baixos valores de coeficiente de correlação obtidos nos ajustes lineares se devem à utilização de poucos pontos experimentais inerente à condição de processos em frascos sob agitação, que limitam a retirada de amostras (Figura 4).

A partir dos resultados gerais obtidos nas três condições testadas, apresentados na Tabela 1, pode-se verificar que o pico de concentração celular $\left(\mathrm{X}_{\max }\right)$ foi observado em menor tempo e em valor superior nos ensaios F5 e F10 em relação ao controle. Os valores da máxima velocidade específica de crescimento $\left(\mu_{\mathrm{X}, \max }\right)$ foram semelhantes nas três condições, $0,10,0,12$ e $0,10 \mathrm{~h}^{-1}$ para o ensaio controle, F5 e F10, respectivamente, indicando que a utilização de inóculo vegetativo não promoveu queda da máxima velocidade específica de crescimento, ao contrário do que foi observado por Papagianni e Moo-Young (2002), utilizando $A$. niger para a produção de glicoamilases. Adicionalmente, o início da fase 
exponencial de crescimento foi observado em menor tempo de cultivo quando se utilizou qualquer proporção de inóculo vegetativo.

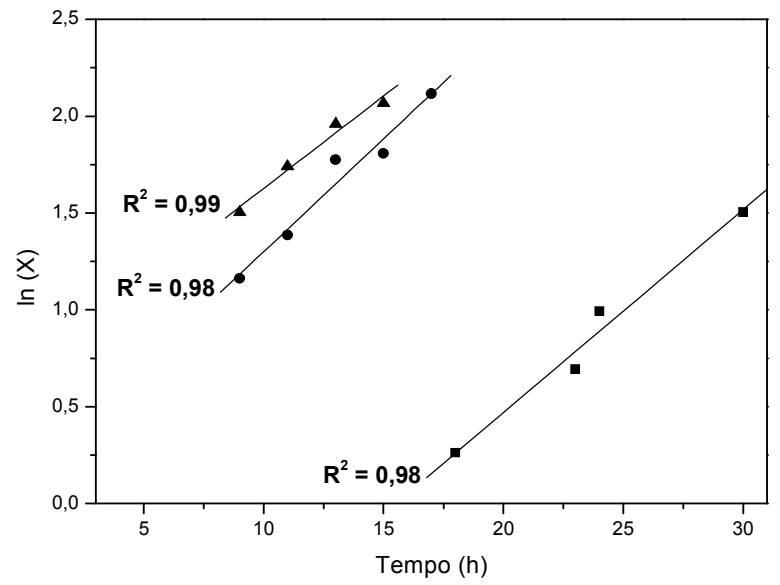

Figura 4 - Representação semilogarítmica da concentração celular em função do tempo de cultivo de Aspergillus fumigatus, com diferentes formas de inoculação: (๘) Ensaio Controle:

inóculo de esporos; $(\bullet)$ F5: inóculo vegetativo $(5 \% \mathrm{v} / \mathrm{v}) ;(\boldsymbol{\Delta})$ F10: inóculo vegetativo

$(10 \% \mathrm{v} / \mathrm{v}) .(\mathbf{-})$ ajuste linear dos pontos experimentais.

No ensaio controle, o pico de atividade enzimática $(9,0 \mathrm{U} / \mathrm{mL})$ foi observado em $120 \mathrm{~h}$ de cultivo. Em F5 e F10 observou-se um leve aumento de atividade de pectinases totais, alcançando valores máximos em $75 \mathrm{~h}$, em média 11 e $13 \mathrm{U} / \mathrm{mL}$, respectivamente, mantendo-se neste patamar até o final dos cultivos. Considerando que os picos de atividade enzimática ocorreram cerca de $45 \mathrm{~h}$ antes nos ensaios F5 e F10, foram obtidos maiores valores de produtividade volumétrica $\left(\mathrm{p}_{\mathrm{v}}\right)$ nestas condições. Adicionalmente, foram obtidos os maiores valores de fator de conversão de substrato em células ( $\left.\mathrm{Y}_{\mathrm{X} / \mathrm{S}}\right)$ e em produto/pectinases $\left(\mathrm{Y}_{\mathrm{P} / \mathrm{S}}\right)$.

Tabela 1 - Resultados gerais de cultivos de Aspergillus fumigatus, em frascos sob agitação, com diferentes formas de inoculação

\begin{tabular}{l|ccc}
\hline & Controle & $\mathbf{F 5}$ & $\mathbf{F 1 0}$ \\
\hline $\mathbf{X}_{\max }(\mathbf{g} / \mathbf{L})$ & 12,6 & 14,1 & 14,6 \\
$\mathbf{t}_{\mathbf{X}, \max }(\mathbf{h})$ & 51 & 43 & 41 \\
$\boldsymbol{\mu}_{\mathbf{X}, \max }\left(\mathbf{h}^{-\mathbf{1}}\right)$ & 0,104 & 0,116 & 0,095 \\
$\mathbf{t}_{\mathbf{e x p}}(\mathbf{h})$ & $18-30$ & $9-17$ & $9-15$ \\
$\mathbf{P}_{\max }(\mathbf{U} / \mathbf{m L})$ & 9,0 & 11,0 & 13,0 \\
$\mathbf{t}_{\mathbf{P}, \max }(\mathbf{h})$ & 120 & 75 & 75 \\
$\mathbf{Y}_{\mathbf{X} / \mathbf{s}}(\mathbf{g} / \mathbf{g})$ & 0,65 & 0,79 & 0,76 \\
$\mathbf{Y}_{\mathbf{P} / \mathbf{S}}(\mathbf{U} / \mathbf{m g})$ & 0,45 & 0,56 & 0,57 \\
$\mathbf{p}_{\mathbf{V}}(\mathbf{U} / \mathbf{m L} / \mathbf{h})$ & 0,077 & 0,151 & 0,176 \\
\hline
\end{tabular}

$\mathrm{X}_{\max }$ - máxima concentração de biomassa; $t_{\mathrm{X}, \max }$ - tempo em que ocorreu $\mathrm{X}_{\max } ; \mu_{\mathrm{X}, \max }-$ máxima velocidade específica de crescimento celular; $t_{\exp }$ - intervalo de tempo do cultivo caracterizado como fase exponencial, no qual foi determinada $\mu_{\mathrm{X}, \max } ; \mathrm{P}_{\max }$ - máxima atividade de pectinases; $\mathrm{t}_{\mathrm{P}, \max }$ - tempo em que ocorreu $\mathrm{P}_{\max } ; \mathrm{Y}_{\mathrm{X} / \mathrm{S}}-$ fator de conversão de substrato em células; $\mathrm{Y}_{\mathrm{P} / \mathrm{S}}$ - fator de conversão de substrato em pectinases; $\mathrm{p}_{\mathrm{V}}-$ produtividade volumétrica.

Controle: suspensão de esporos; F5 e F10: inóculo vegetativo (5 e 10\% v/v). 


\section{CONCLUSÃO}

Os dados obtidos neste trabalho indicam a forte influência exercida pelo tipo de inóculo sobre o crescimento celular e o tempo de processo de obtenção de pectinases por $A$. fumigatus em cultivos realizados em frascos sob agitação. $\mathrm{O}$ tempo necessário para que a fase exponencial de crescimento fosse atingida, empregando 5 ou $10 \%$ (v/v) de inóculo vegetativo, foi reduzido em cerca de 9 horas em comparação ao controle, sem promover redução na máxima velocidade específica de crescimento. Nestas condições foram obtidos resultados superiores de concentração de biomassa e a produção de pectinases foi antecipada em cerca de 45 horas, levando à obtenção de altos valores de produtividade volumétrica em relação ao cultivo inoculado com esporos.

Estes resultados sugerem a possibilidade de uso de inóculo vegetativo em estudos posteriores em biorreator como forma de reduzir o tempo e o custo operacional do processo de produção de pectinases por A. fumigatus.

\section{APOIO}

UCS, CAPES, CNPq e FAPERGS.

\section{REFEREÊNCIAS BIBLIOGRÁFICAS}

BRASIL. Agência Nacional de Vigilância Sanitária. RDC N 26 de 26 de maior de 2009. Aprova a lista de enzimas permitidas para uso em alimentos destinados ao consumo humano conforme a sua origem, constante do Anexo desta Resolução, em substituição ao Anexo I da Resolução RDC N 205 de 14 de novembro de 2006. Disponível (online): http://bvsms.saude.gov.br/ bvs/saudelegis/anvisa/2009/res0026_26_05_2009.html (24 de fevereiro de 2014).

BITTMAN, R. Analysis of reducing sugars in breakfast cereal and other foods. J. Chem. Education. v. 51, p. 49, 1974.

FONTANA, R.C.; POLIDORO, T.A.; SILVEIRA, M.M. Comparision of stirred tank and airlift bioreactors in the production of polygalacturonases by Aspergillus oryzae. Bioresour. Technol. v. 100, p. 4493-4498, 2009.

GUMMADI, S.N.; PANDA, T. Purification and biochemical properties of microbial pectinases: a review. Process Biochem. v. 38, p. 987-996, 2003.

HISS, H. Cinética de processos fermentativos. In: SCHMIDELL, W.; LIMA, U. E.; AQUARONE, E.; BORZANI, W. Biotecnologia Industrial: Engenharia Bioquímica. Vol. 2. São Paulo: Edgard Blucher Ltda. pp 93-122, 2001.

JAYANI, R.S.; SAXENA, S.; GUPTA, R. Microbial pectinolytic enzymes: a review. Process Biochem. v. 40, p. 2931-2944, 2005. 
KASHYAP, D.R.; VOHRA, P.K.; CHOPRA, S.; TEWARI, R. Applications of pectinases in the commercial sector: a review. Bioresour. Technol. v. 77, p. 215-227, 2001.

MALVESSI, E. Estudo de produção de poligalacturonases por Aspergillus oryzae em processo submerso. Dissertação de mestrado. Instituto de Biotecnologia, Universidade de Caxias do Sul, 2000 .

MALVESSI, E.; SILVEIRA, M.M. Influence of medium composition and $\mathrm{pH}$ on the production of polygalacturonases by Aspergillus oryzae. Braz. Arch. Biol Technol. v. 47, p. 693-702, 2004.

MAIORANO, A.E. Produção de pectinase por fermentação em estado sólido. Tese de doutorado. Escola Politécnica da Universidade de São Paulo, 1990.

MORAES, I. O. Produção de microrganismos. In: LIMA, U.E.; AQUARONE, E.; BORZANI, W.; SCHMIDELL, W. Biotecnologia Industrial: Processos fermentativos e enzimáticos. Vol. 3. São Paulo: Edgard Blucher Ltda. pp 199-217, 2001.

PAPAGIANNI, M.; MOO-YOUNG, M. Protease secretion in glucoamylase producer Aspergillus niger cultures: fungal morphology and inoculums effects. Process Biochem. v. 37, p.1271-1278, 2002.

UENOJO, M.; PASTORE, G.M. Pectinases: aplicações industriais e perspectivas. Quím. Nova. v. 30, p. 388-394, 2007.

UEDA, S.; FUJIO, Y.; LIM, J.Y. Production and some properties of pectic enzymes from Aspergillus oryzae A3. J. Appl. Biochem. v. 4, p. 524-532, 1982. 